Subscriber access provided by Caltech Library

\title{
Letter
}

\section{Predicted Structures of the Active Sites Responsible for the Improved Reduction of Carbon Dioxide by Gold Nanoparticles}

Tao Cheng, Yufeng Huang, Hai Xiao, and William A. Goddard III

J. Phys. Chem. Lett., Just Accepted Manuscript • DOI: 10.1021/acs.jpclett.7b01335 • Publication Date (Web): 04 Jul 2017

Downloaded from http://pubs.acs.org on July 6, 2017

\section{Just Accepted}

"Just Accepted" manuscripts have been peer-reviewed and accepted for publication. They are posted online prior to technical editing, formatting for publication and author proofing. The American Chemical Society provides "Just Accepted" as a free service to the research community to expedite the dissemination of scientific material as soon as possible after acceptance. "Just Accepted" manuscripts appear in full in PDF format accompanied by an HTML abstract. "Just Accepted" manuscripts have been fully peer reviewed, but should not be considered the official version of record. They are accessible to all readers and citable by the Digital Object Identifier (DOI®). "Just Accepted" is an optional service offered to authors. Therefore, the "Just Accepted" Web site may not include all articles that will be published in the journal. After a manuscript is technically edited and formatted, it will be removed from the "Just Accepted" Web site and published as an ASAP article. Note that technical editing may introduce minor changes to the manuscript text and/or graphics which could affect content, and all legal disclaimers and ethical guidelines that apply to the journal pertain. ACS cannot be held responsible for errors or consequences arising from the use of information contained in these "Just Accepted" manuscripts. 


\title{
Predicted Structures of the Active Sites Responsible
}

\section{for the Improved Reduction of Carbon Dioxide by}

\author{
Gold Nanoparticles
}

Tao Cheng, Yufeng Huang, Hai Xiao and William A Goddard III*

Materials and Process Simulation Center (MSC) and

Joint Center for Artificial Photosynthesis (JCAP),

California Institute of Technology, Pasadena, California 91125, United States

\author{
AUTHOR INFORMATION \\ Corresponding Author \\ *E-mail: wag@wag.caltech.edu.
}


ABSTRACT: Gold (Au) nanoparticles (NPs) are known experimentally to reduce carbon dioxide $\left(\mathrm{CO}_{2}\right)$ to carbon monoxide $(\mathrm{CO})$, with far superior performance to Au foils. To obtain guidance in designing improved $\mathrm{CO}_{2}$ catalysts, we want to understand the nature of the active sites on $\mathrm{Au}$ NPs. Here, we employed multiscale atomistic simulations to computationally synthesize and characterize a $10 \mathrm{~nm}$ thick $\mathrm{Au} \mathrm{NP}$ on a carbon nanotube (CNT) support, and then we located active sites from quantum mechanics (QM) calculations on 269 randomly-selected sites. The standard scaling relation is that the formation energy of $* \mathrm{COOH}\left(\Delta E_{*} \mathrm{COOH}\right)$ is proportional to the binding energy of $* \mathrm{CO}\left(E^{\text {binding }}{ }^{*} \mathrm{CO}\right)$ so decreasing $\Delta E_{*_{\mathrm{COOH}}}$ to boost the $\mathrm{CO}_{2}$ reduction reaction $\left(\mathrm{CO}_{2} \mathrm{RR}\right)$ causes an increase of $E^{\text {binding }}{ }^{*} \mathrm{CO}$ that retards $\mathrm{CO}_{2} \mathrm{RR}$. We show that the NPs has superior $\mathrm{CO}_{2} \mathrm{RR}$ because there are many sites at the twin boundaries that significantly break this scaling relation.

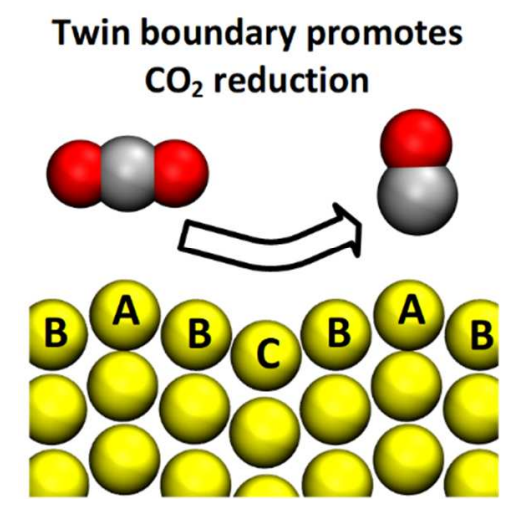


There is great interest in remediating the rapid increase of atmospheric carbon dioxide $\left(\mathrm{CO}_{2}\right)$ concentrations with its associated increase in global temperature. ${ }^{1}$ One strategy is to develop improved catalysts for the electrochemical reduction of $\mathrm{CO}_{2}$ to value-added chemicals, such as carbon monoxide $(\mathrm{CO})$, methane $\left(\mathrm{CH}_{4}\right)$, ethylene $\left(\mathrm{C}_{2} \mathrm{H}_{4}\right)$ and ethanol $\left(\mathrm{C}_{2} \mathrm{H}_{5} \mathrm{OH}\right) .{ }^{2-3}$

Of the metals known to reduce $\mathrm{CO}_{2}$ to $\mathrm{CO}$ efficiently, Gold (Au) exhibits the highest activity and selectivity among polycrystalline metals. As first reported by Hori et al., ${ }^{4}$ the Faradaic efficiency for $\mathrm{CO}$ formation is $91 \%$ at $-1.10 \mathrm{~V}$ vs. normal hydrogen electrode (NHE) [or $-0.69 \mathrm{~V}$ vs. reversible hydrogen electrode (RHE)] with a partial current density of $3.7 \mathrm{~mA} \mathrm{~cm}$. Moreover, Au nanoparticles (NPs) have been shown to improve the $\mathrm{CO}_{2} \mathrm{RR}$ performance further. For example, Chen et al. reported that an Au NP derived from Au oxide films results in $\mathrm{CO}_{2} \mathrm{RR}$ to $\mathrm{CO}$ with Faraday efficiency more than $60 \%$ at overpotentials as low as $0.14 \mathrm{~V}(-0.25 \mathrm{Vvs}$ RHE). ${ }^{5}$ Feng et al. found a linear relationship between $\mathrm{CO}_{2} \mathrm{RR}$ performance and the density of GBs in NPs, ${ }^{6}$ concluding that the presence of grain boundaries (GBs) on Au NPs is responsible for the improved $\mathrm{CO}_{2} \mathrm{RR}$ performance. In addition, $\mathrm{Zhu}$ et al. concluded that for crystalline $\mathrm{Au}$ NPs, edge sites are the active sites for $\mathrm{CO}_{2} \mathrm{RR}^{7-8}$ They also showed that the size of the Au NPs is critical for controlling reaction rates: $8 \mathrm{~nm} \mathrm{Au} \mathrm{NPs} \mathrm{exhibit} \mathrm{the} \mathrm{best} \mathrm{CO}_{2} \mathrm{RR}$ performance, ${ }^{7}$ while NPs below $2 \mathrm{~nm}$ are active only for hydrogen evolution reactions (HER). ${ }^{9}$ Of course, the applied electric field and the electrolyte can also influence $\mathrm{CO}_{2} \mathrm{RR}$. Using Au Nano-needles as catalysts, Liu et al. confirm that a field-induced 20 -fold increased surface-adsorbed $\mathrm{K}^{+}$ion concentration enables $\mathrm{CO}_{2} \mathrm{RR}$ to proceed with a partial current density for $\mathrm{CO}$ of $22 \mathrm{~mA} \mathrm{~cm}$ at $-0.35 \mathrm{~V}$ (RHE), the best experimental results reported. ${ }^{10}$ Alloying $\mathrm{Au}^{11}$ or suppressing $\mathrm{HER}^{12}$ are another directions to improve CO2RR. 
Resolving the atomic structure of active sites responsible for the improved performance of $\mathrm{Au}$ NPs should provide clues helpful in designing improved $\mathrm{CO}_{2} \mathrm{RR}$ catalysts. However, detection of the active sites directly from the experiment has not been possible. We report here computer simulation experiments aimed at synthesizing, characterizing, and resolving the actives sites for $\mathrm{CO}_{2} \mathrm{RR}$ on $\mathrm{Au} \mathrm{NP}$.

First, we computationally mimic the experimental chemical vapor deposition (CVD) of a 10 $\mathrm{nm}$ Au NP on $44.28 \mathrm{~nm}$ long, $8.39 \mathrm{~nm}$ diameter multiwall carbon nanotube (CNT) support. Here we carried out Reactive Molecular Dynamics (RMD) simulations of Au deposition on a 10nm diameter CNT using the Embedded-Atom Model (EAM) to describe the Au-Au interactions. ${ }^{13}$ The CVD experiments use an e-beam evaporated $\mathrm{Au}$ source, which we mimic by adding Au atoms into the simulation cell with a deposition rate of $3.0 \AA \mathrm{ns}^{-1}$ for $35 \mathrm{~ns}$ (the experiment deposition rate is $2 \AA^{-1}$ for $50 \mathrm{~s}$ ).

We observed the rapid development of supersaturated $\mathrm{Au}$ vapor that in $0.3 \mathrm{~ns}$ began to condense. As the concentration of $\mathrm{Au}$ vapor reached $0.5 \mathrm{Au}$ atom $/ \mathrm{nm}^{3}$, we observed the formation of $\mathrm{Au}$ nuclei containing $\sim 18$ atoms on the CNT surface that grew quickly in various directions until their boundaries met. After 35 ns, we obtained a coarse Au NP on CNT with a nominal thickness of about $10 \mathrm{~nm}$, which is consistent with the size of the experimental catalyst.

Then, we employed simulated annealing to heal the defects arising from the fast deposition rate. The peak temperature in the simulated annealing is $1,164 \mathrm{~K}$ (100K higher than the experimental melting point of Au metal). Each annealing cycle contained a ten ps heating ramp from $300 \mathrm{~K}$ to $1,164 \mathrm{~K}$ followed by five ps NVT simulation at $1164 \mathrm{~K}$, and then a 10 ps cooling ramp from $1,164 \mathrm{~K}$ to $300 \mathrm{~K}$. Finally, we carried out a 15 ps NVT simulation at $300 \mathrm{~K}$. After 120 such annealing cycles; we found that all grains boundaries disappeared to form a single fully- 
crystallized Au NP. From the annealing trajectories, we extracted an Au NP structure that most closely resembled the experiment catalyst (after 63 annealing cycles).

To further refine the Au NP structure and the interface between the Au NP and the CNT support, we carried out 20 ps of reactive dynamics at $300 \mathrm{~K}$ using the ReaxFF reactive force field trained to reproduce the equation of state of Au FCC metal and the geometry of graphene on the $\mathrm{Au}$ (111) surface. ${ }^{14}$ Finally, we removed under-coordinated Au atoms (with coordination number less than five) expected to be washed away under the experimental conditions. The final Au NP structure consists of 211,619 atoms (43,200 Carbon atoms $+168,419$ Au atoms) with a nominal thickness of $10 \mathrm{~nm}$, as shown in Figure 1A.

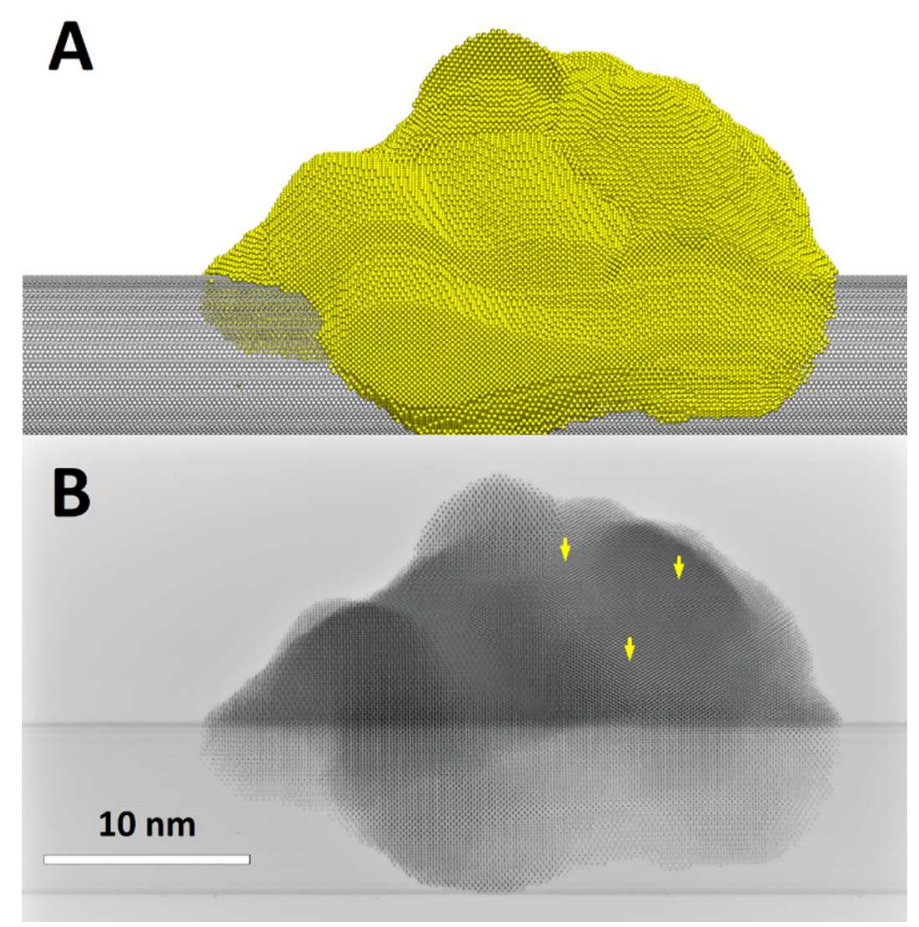

Figure 1. (A) The atomic structure of the Au nanoparticle (NP) "synthesized" computationally by simulating the Chemical Vapor Deposition (CVD) experiment. (B) Predicted Transmission electron microscopy (TEM) images of the predicted Au NP. The yellow marker label three of the grain boundaries (GBs). 
This NP leads to an X-Ray Powder Diffraction (XRD) pattern (see Figure S1) showing the typically broadened diffraction peaks of FCC Au due to the small grains, which is consistent with experiment. Our predicted TEM images (Figure 1B) show the GBs in the Au-NP, while our dislocation analysis reveals that $1 / 6<112>$ Shockley partial dislocations are the most abundant, leading to stacking faults on the surface. The total length of this dislocation is $3,224 \AA$, which corresponds to a GB density of $224 \mu \mathrm{m}^{-1}$ (as defined experimentally). ${ }^{15}$ The XRD pattern and TEM images which confirm that the simulated Au NP structure is consistent with experiment.

In our previous work ${ }^{16}$ and research from other groups, ${ }^{17-19}$ the reaction mechanism of $\mathrm{CO}_{2} \mathrm{RR}$ to $\mathrm{CO}$ on copper $(\mathrm{Cu})$ is as following:

$$
l-\mathrm{CO}_{2} \rightarrow * b-\mathrm{CO}_{2}^{\delta-} \rightarrow * \mathrm{COOH} \rightarrow * \mathrm{CO} \rightarrow \mathrm{CO}
$$

In this pathway, physisorbed linear $\mathrm{CO}_{2}\left[l-\mathrm{CO}_{2}\right]$ was first reduced to chemisorbed $\mathrm{CO}_{2}(b$ $\left.\mathrm{CO}_{2}{ }^{\delta-}\right)$ facilitated by a partial electron transfer $\left(\delta \cdot e^{-}\right)$. In our previous work using PBE-D3 density functional theory (DFT) calculations on the $\mathrm{Cu}(100)$ surface with 5 layers of $\mathrm{H}_{2} \mathrm{O}$, we found that $b-\mathrm{CO}_{2}{ }^{\delta}$ is in a mixed coordination structure with one C-O bond (1.33 $\AA$ ) parallel to the surface and one bond $\left(1.29 \AA\right.$ ) tilted by $\sim 60^{\circ} .{ }^{16}$ These distances are close to the C-O bond (1.26) of free $\mathrm{CO}_{2}^{-}$.The following proton-coupled electron transfer $\left[(1-\delta) \cdot e^{-}\right]$reaction leads to ${ }^{*} \mathrm{COOH}$ formation, which completes the first electron reduction reaction. The ${ }^{*} \mathrm{COOH}$ dehydration reduction reaction leads to ${ }^{*} \mathrm{CO}$ formation. Finally, ${ }^{*} \mathrm{CO}$ desorbs and releases the reaction site completing the catalysis cycle. In this reaction pathway, $b-\mathrm{CO}_{2}{ }^{\delta-}$ formation is the ratedetermining step (RDS), and ${ }^{*} \mathrm{COOH}$ formation is the potential-determining step (PDS). Therefore, we took the formation energy of $\operatorname{RDS}\left(\Delta E_{* \mathrm{COOH}}\right)$ as a descriptor (as previously proposed by Peterson and Nørskov) ${ }^{20}$ to characterize the activity of surface sites toward $\mathrm{CO}_{2} \mathrm{RR}$ :

$$
\Delta E_{* \mathrm{COOH}}=E_{*} \mathrm{COOH}-\left(E_{*}+E_{\mathrm{CO} 2}+0.5 \times E_{\mathrm{H} 2}\right)
$$


A lower $\Delta \mathrm{E} * \mathrm{COOH}$ indicates increased $\mathrm{CO}_{2} \mathrm{RR}$. We also calculated the energy of $\mathrm{CO}$ desorption $\left(\Delta E_{* \mathrm{CO}}\right)$

$$
\Delta E_{\mathrm{CO}}=\left(E_{*}+E_{\mathrm{CO}}\right)-E_{* \mathrm{CO}}
$$

This non-electrochemical reaction step determines the rate of $\mathrm{CO}$ is leaving the surface sites: the lower $\Delta E *_{\mathrm{CO}}$ indicates, the higher $\mathrm{CO}_{2} \mathrm{RR}$.

Thus the binding energy of $\mathrm{CO}$ can be written as:

$$
E^{\text {binding }}{ }_{* \mathrm{CO}}=E_{* \mathrm{CO}}-\left(E_{*}+E_{\mathrm{CO}}\right)=-\Delta E_{* \mathrm{CO}}
$$

To extract the active sites on Au NP, we randomly selected 269 sites out of 11,360 sites (2.4\%) from the catalysis surface. This random sampling introduces no presumptions, ensuring that the statistical distribution represents the overall distribution of the reactive sites. We calculated $\Delta E * \mathrm{COOH}$ and $\Delta E_{\mathrm{CO}}$ using cluster models. These cluster models were cut from the simulated nanoparticle by taking the selected sites as the center with a cut-off of $8 \AA$. Such $8 \AA$ provides a computational accuracy $0.02 \mathrm{eV}$, which we considered as the best balance of accuracy and efficiency.

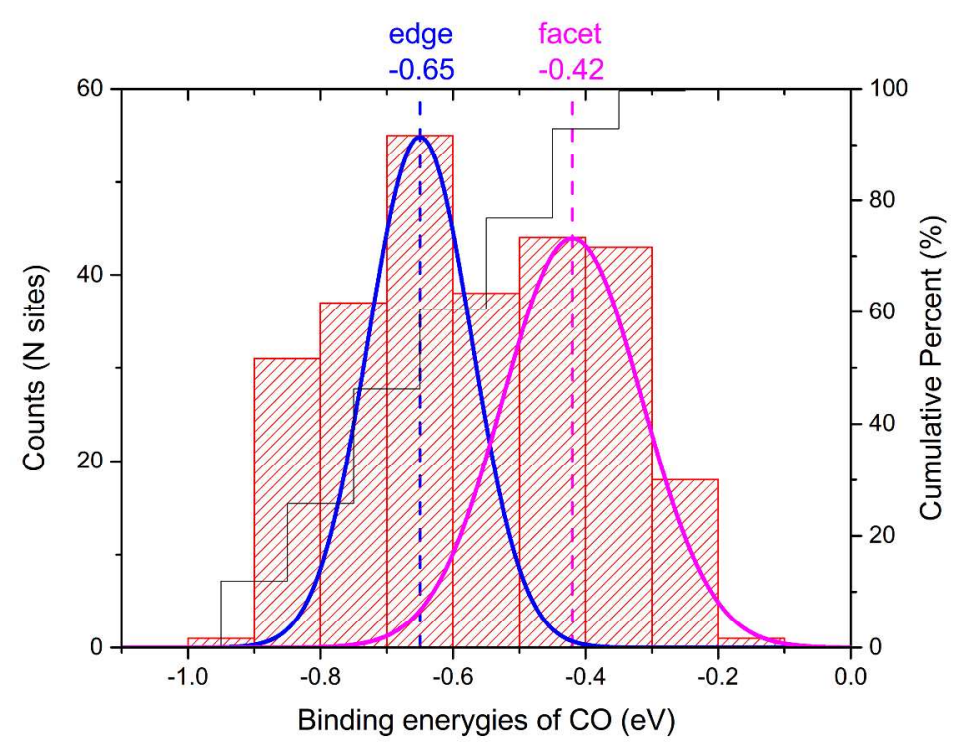


Figure 2. The distribution of $\mathrm{CO}$ binding energies $\left(E^{\text {binding }} \mathrm{CO}\right.$, in eV) from PBE-D2 DFT on 269 Au NP surface sites selected randomly. The solid black line refers to the right axis as the cumulative percent (\%). Two Gaussian functions were employed to fit the binding energies. One takes $-0.65 \mathrm{eV}\left(\Delta E_{*_{\mathrm{CO}}}\right.$ of edge site) as the center with a width of $0.077 \mathrm{eV}$ (in blue), and the other takes $-0.42 \mathrm{eV}\left(\Delta E_{* \mathrm{CO}}\right.$ of facet site) as the center with a width of $0.105 \mathrm{eV}$ (in purple).

Figure 2 shows the statistical distribution of $E^{\text {binding }} \mathrm{CO}$ of 269 surface sites ranging from $-0.1 \mathrm{eV}$ to $-0.9 \mathrm{eV}$. To compare with the fully crystalline $\mathrm{Au} \mathrm{NP}$, we built an Au octahedron (shown in Figure S2) with a length of $6.93 \mathrm{~nm}(10,425 \mathrm{Au}$ atoms), which consists of 2,024 facet sites (87.77\%), 276 edge sites $(11.97 \%)$ and six corner sites $(0.26 \%)$. The DFT CO energy changes (negative is bound), $E^{\text {binding }} \mathrm{CO}$, are $-0.42 \mathrm{eV}$ facet site and $-0.65 \mathrm{eV}$ edge site. Taking these two energies as a reference, we fitted the $\Delta E{ }^{*} \mathrm{CO}$ distribution using Gaussian functions centering at $0.42 \mathrm{eV}$ and $-0.65 \mathrm{eV}$ as shown in Figure 2. This fitting indicates that the most abundant binding site are rhombus sites [(111)-like sites] and step sites [(110)-like sites]. These predictions are consistent with experimental electrochemical surface characterizations showing that (111) and (110) facet are dominant. ${ }^{6}$ However, the distribution on our CVD derived Au NP is much broader than for the polyhedron crystalline Au NP due to the additional defects created by CVD deposition (primarily GBs and twin boundaries). This broad variation in binding site provides a site library, among which active sites exist responsible for $\mathrm{CO}_{2} \mathrm{RR}$.

We observed the standard scaling relation, a negative correlation between $\Delta E_{*} \mathrm{COOH}$ and $\Delta E_{\mathrm{CO}}$ (as shown in Figure 3), with a slope of -0.98 . These results are consistent with previous DFT calculations. ${ }^{21-23}$ Both small $\Delta E_{* \mathrm{COOH}}$ (corresponding to a low overpotential) and $\Delta E_{\mathrm{CO}}$ (promote $\mathrm{CO}$ desorption) are favorable to promote CO2RR. The negative correlation indicates that reduction in overpotential (decrease of $\Delta E_{* \mathrm{COOH}}$ ) occurs at the expense of increasing the $\mathrm{CO}$ 
adsorption (an increase of $\Delta E_{\mathrm{CO}}$ ). The sites with strong $\mathrm{CO}$ binding (large $\Delta E_{\mathrm{CO}}$ ) are also responsible for promoting the hydrogen evolution reaction (HER), therefore suppressing $\mathrm{CO}_{2} \mathrm{RR} .{ }^{9}$ The optimal sites for $\mathrm{CO}_{2} \mathrm{RR}$ is a balance between $\Delta E *_{\mathrm{COOH}}$ and $\Delta E_{\mathrm{CO}}$. Experimental results suggest that edge sites provide the best balance, increasing activity for $\mathrm{CO}_{2} \mathrm{RR}$. Facet sites have a $\Delta E *_{\mathrm{COOH}}$ that is too large, leading to high overpotential, while corner sites have exhibited strong binding for ${ }^{*} \mathrm{CO}$ and ${ }^{*} \mathrm{H}$, which favors HER. Therefore, the surface sites responsible for promoting $\mathrm{CO}_{2} \mathrm{RR}$ on the $\mathrm{Au} \mathrm{NP}$ are expected to be those highlighted in the upper left part of Figure 3. which exhibit smaller $\Delta E_{*_{\mathrm{COOH}}}$ without increasing $\Delta E_{\mathrm{CO}}$ (site $\alpha$ ) or reducing $\Delta E_{\mathrm{CO}}$ without increasing $\Delta E_{*} \mathrm{COOH}($ site $\beta)$ as highlighted in Figure 3.

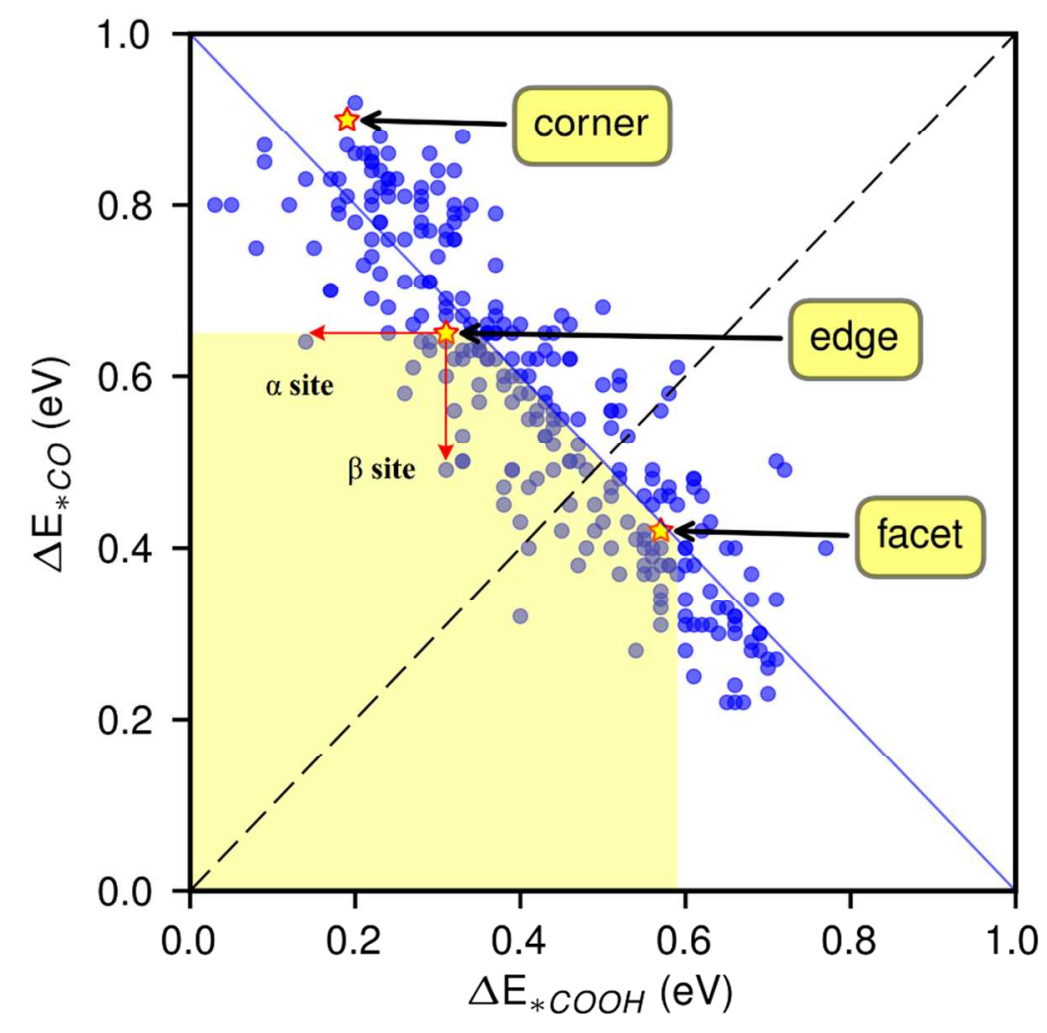

Figure 3. The reaction energy of $* \mathrm{COOH}$ formation $\left(\left(\Delta E_{* \mathrm{COOH}}\right)\right.$ versus the binding energy of ${ }^{*} \mathrm{CO}\left(\Delta E *_{\mathrm{CO}}\right)$. The blue circles are the results of 269 surface sites from random sampling. The yellow stars are the results of the facet, edge and corner sites on Au octahedron (as shown in 
Figure S2). The yellow filled region highlight the sites breaking linear scaling relationship (promote $\mathrm{CO}_{2} \mathrm{RR}$ ). The red arrows highlight two sites ( $\alpha$ site and $\beta$ site) with $\mathrm{CO}_{2} \mathrm{RR}$ performance better than edge site as predicted.
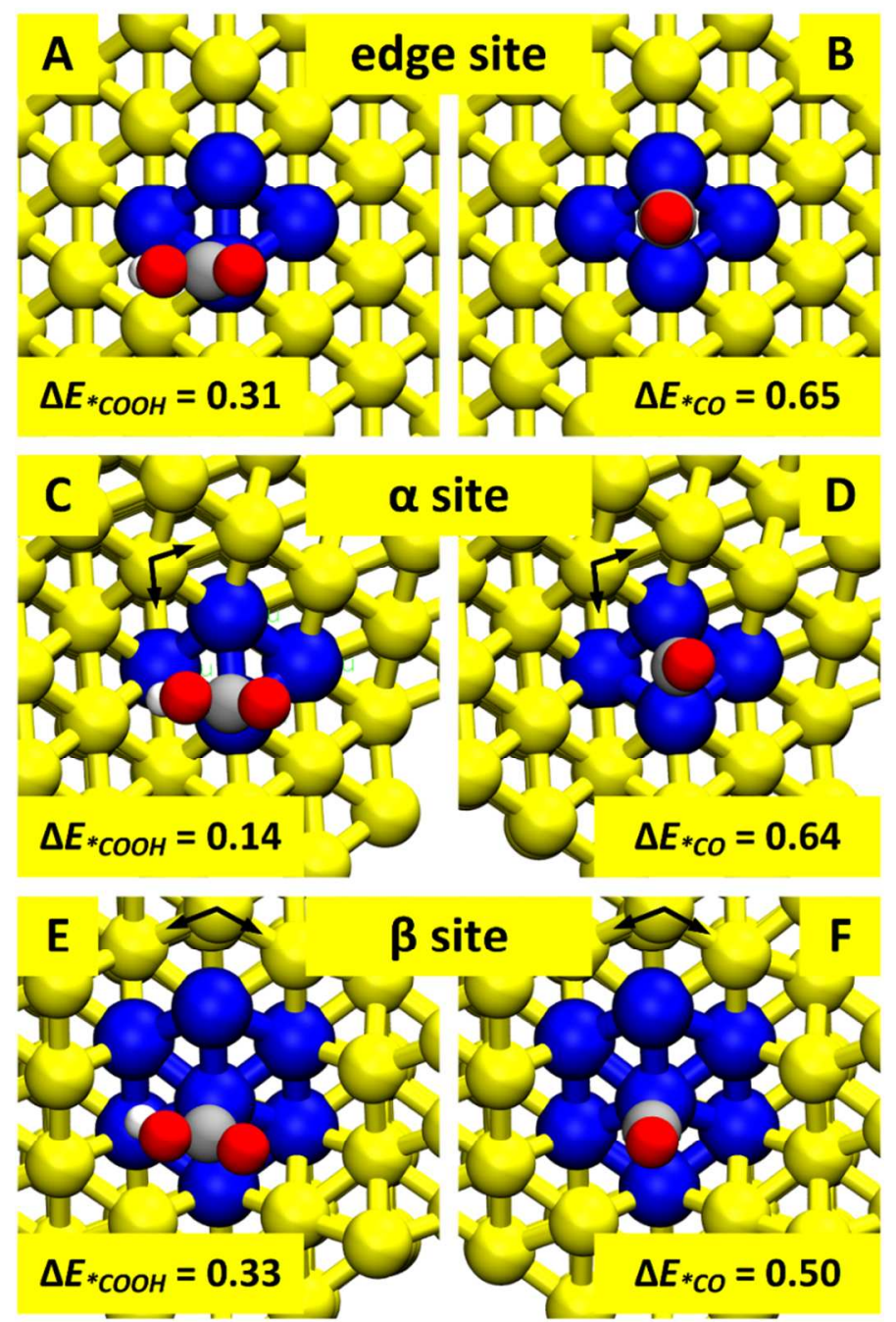

Figure 4. ${ }^{*} \mathrm{CO}$ binding on edge site (A), $\alpha$ site $(\mathrm{C})$ and $\beta$ site $(\mathrm{E}) .{ }^{*} \mathrm{COOH}$ binding on edge site (B), a site (D) and b site (F). The colors are Au in yellow, $\mathrm{C}$ in silver, $\mathrm{H}$ in white and $\mathrm{O}$ in red. We highlighted the binding sites in blue for viewing convenience. Black arrows show the directions of the twin boundaries. 
Therefore, these two sites should be superior in increasing $\mathrm{CO}_{2} \mathrm{RR}$. Figure $4 \mathrm{C}$ and Figure 4D show ${ }^{*} \mathrm{COOH}$ and ${ }^{*} \mathrm{CO}$ on $\alpha$ site. Figure $4 \mathrm{E}$ and Figure $4 \mathrm{~F}$ show $* \mathrm{COOH}$ and ${ }^{*} \mathrm{CO}$ on $\beta$ site. The common feature of these two sites is that they are on the twin boundaries. To compare, Figure $4 \mathrm{~A}$ and Figure $4 \mathrm{~B}$ show ${ }^{*} \mathrm{COOH}$ and ${ }^{*} \mathrm{CO}$ on edge site. The $\alpha$ site lies on the twin boundary leading to a $0.17 \mathrm{eV}$ decrease in $\Delta E_{*_{\mathrm{COOH}}}(0.14 \mathrm{eV})$ compared to $0.31 \mathrm{eV}$ for an edge site, while he $\Delta E_{\mathrm{CO}}$ does not change $(0.64 \mathrm{eV}$ vs. $0.65 \mathrm{eV})$. For the $\beta$ site, the rhombus site lies on the twin boundary leading to $0.26 \mathrm{eV}$ decrease in $\Delta E_{* \mathrm{COOH}}(0.33 \mathrm{eV})$ compared with that $(0.59 \mathrm{eV})$ of a facet site, which is very close to the $\Delta E_{* \mathrm{COOH}}(0.31 \mathrm{eV})$ of an edge site, while $\Delta E_{\mathrm{CO}}$ decreases by $0.14 \mathrm{eV}(0.50$ vs. $0.36 \mathrm{eV})$, which is less than the increase in $\Delta E_{* \mathrm{COOH}}$. Therefore, these surface sites on twin boundaries are superior in $\mathrm{CO}_{2} \mathrm{RR}$, because they significantly decrease $\Delta E_{* \mathrm{COOH}}$.

To summarize, we employed multiscale simulations to computationally "synthesize" an Au NP with a thickness of $10 \mathrm{~nm}$ on a CNT support. The XRD of this Au NP (Figure S1) shows the FCC crystal structure, consistent with the experimental results. The simulated TEM image (Figure 1B) show clear GB structures. A dislocation analysis shows that $1 / 6<112>$ Shockley partial dislocations are most abundant, which induces stacking defects on the surface.

To locate the active sites for $\mathrm{CO}_{2} \mathrm{RR}$, we randomly selected 269 response sites out of 11,360 total sites (2.4\%) for QM calculations. The QM results show a linear relationship between the $\Delta E_{* \mathrm{COOH}}$ and $\Delta E_{\mathrm{CO}}$, showing that most sites exhibit the normal scaling relationship between *COOH stabilization, *CO desorption, and HER. However, we find a substantial fraction (10\%) of NP sites on grain boundaries or twin boundaries that significantly decrease $\Delta E *^{*} \mathrm{COOH}$ without increasing $\Delta E_{\mathrm{CO}}$, leading to superior $\mathrm{CO}_{2} \mathrm{RR}$ performance.

\section{AUTHOR INFORMATION}




\begin{abstract}
Notes
The authors declare no competing financial interests.

ACKNOWLEDGMENT

This work was supported by the Joint Center for Artificial Photosynthesis, a DOE Energy Innovation Hub, supported through the Office of Science of the U.S. Department of Energy under Award No. DE-SC0004993. This work used the Extreme Science and Engineering Discovery Environment (XSEDE) which is supported by National Science Foundation grant number ACI-1053575, and the Zwicky Astrophysics supercomputer at Caltech.
\end{abstract}

Supporting Information Available: Simulation details, Simulated XRD patterns, Equation of state of FCC Au, an Au octahedral model and ReaxFF parameters of Au and C. 


\section{REFERENCES}

(1) Foster, G. L.; Royer, D. L.; Lunt, D. J. Future Climate Forcing Potentially Without Precedent in the Last 420 Million Years. Nat. Commun. 2017, 8, 14845.

(2) Gattrell, M.; Gupta, N.; Co, A. A Review of the Aqueous Electrochemical Reduction of $\mathrm{CO}_{2}$ to Hydrocarbons at Copper. J. Electroanal. Chem. 2006, 594, 1-19.

(3) Kortlever, R.; Shen, J.; Schouten, K. J. P.; Calle-Vallejo, F.; Koper, M. T. M. Catalysts and Reaction Pathways for the Electrochemical Reduction of Carbon Dioxide. J. Phys. Chem. Lett. 2015, 6, 4073-4082.

(4) Hori, Y.; Murata, A.; Kikuchi, K.; Suzuki, S. Electrochemical Reduction of Carbon Dioxides to Carbon Monoxide at a Gold Electrode in Aqueous Potassium Hydrogen Carbonate. J. Chem. Soc., Chem. Commun. 1987, 10, 728-729.

(5) Chen, Y.; Li, C. W.; Kanan, M. W. Aqueous $\mathrm{CO}_{2}$ Reduction at Very Low Overpotential on Oxide-Derived Au Nanoparticles. J. Am. Chem. Soc. 2012, 134, 19969-19972.

(6) Feng, X.; Jiang, K.; Fan, S.; Kanan, M. W. Grain-Boundary-Dependent $\mathrm{CO}_{2}$ Electroreduction Activity. J. Am. Chem. Soc. 2015, 137, 4606-4609.

(7) Zhu, W.; Michalsky, R.; Metin, Ö.; Lv, H.; Guo, S.; Wright, C. J.; Sun, X.; Peterson, A. A.; Sun, S. Monodisperse Au Nanoparticles for Selective Electrocatalytic Reduction of $\mathrm{CO}_{2}$ to CO. J. Am. Chem. Soc. 2013, 135, 16833-16836.

(8) Zhu, W.; Zhang, Y.-J.; Zhang, H.; Lv, H.; Li, Q.; Michalsky, R.; Peterson, A. A.; Sun, S. Active and Selective Conversion of $\mathrm{CO}_{2}$ to $\mathrm{CO}$ on Ultrathin Au Nanowires. J. Am. Chem. Soc. 2014, 136, 16132-16135.

(9) Reske, R.; Mistry, H.; Behafarid, F.; Roldan Cuenya, B.; Strasser, P. Particle Size Effects in the Catalytic Electroreduction of $\mathrm{CO}_{2}$ on $\mathrm{Cu}$ Nanoparticles. J. Am. Chem. Soc. 2014, 136, 6978-6986.

(10) Liu, M.; Pang, Y.; Zhang, B.; De Luna, P.; Voznyy, O.; Xu, J.; Zheng, X.; Dinh, C. T.; Fan, F.; Cao, C., et al. Enhanced Electrocatalytic $\mathrm{CO}_{2}$ Reduction via Field-Induced Reagent Concentration. Nature 2016, 537, 382-386.

(11) Lysgaard, S.; Myrdal, J. S. G.; Hansen, H. A.; Vegge, T. A Dft-Based Genetic Algorithm Search for AuCu Nanoalloy Electrocatalysts for $\mathrm{CO}_{2}$ Reduction. Phys. Chem. Chem. Phys. 2015, 17, 28270-28276.

(12) Wuttig, A.; Yaguchi, M.; Motobayashi, K.; Osawa, M.; Surendranath, Y. Inhibited Proton Transfer Enhances Au-Catalyzed $\mathrm{CO}_{2}$-to-Fuels Selectivity. Proc. Natl. Acad. Sci. U. S. A. 2016, 113, E4585-E4593.

(13) Foiles, S. M.; Baskes, M. I.; Daw, M. S. Embedded-Atom-Method Functions for the FCC Metals $\mathrm{Cu}, \mathrm{Ag}, \mathrm{Au}, \mathrm{Ni}, \mathrm{Pd}, \mathrm{Pt}$, and Their Alloys. Phys. Rev. B: Condens. Matter Mater. Phys. 1986, 33, 7983-7991.

(14) Järvi, T. T.; van Duin, A. C. T.; Nordlund, K.; Goddard, W. A. Development of Interatomic Reaxff Potentials for $\mathrm{Au}-\mathrm{S}-\mathrm{C}-\mathrm{H}$ Systems. J. Phys. Chem. A 2011, 115, 10315-10322.

(15) Feng, X.; Jiang, K.; Fan, S.; Kanan, M. W. A Direct Grain-Boundary-Activity Correlation for CO Electroreduction on Cu Nanoparticles. ACS Cent Sci 2016, 2, 169-174.

(16) Cheng, T.; Xiao, H.; Goddard, W. A. Reaction Mechanisms for the Electrochemical Reduction of $\mathrm{CO}_{2}$ to $\mathrm{CO}$ and Formate on the $\mathrm{Cu}(100)$ Surface at $298 \mathrm{~K}$ from Quantum Mechanics Free Energy Calculations with Explicit Water. J. Am. Chem. Soc. 2016, 138, 13802-13805. 
(17) Luo, W.; Nie, X.; Janik, M. J.; Asthagiri, A. Facet Dependence of $\mathrm{CO}_{2}$ Reduction Paths on $\mathrm{Cu}$ Electrodes. ACS Catal. 2016, 6, 219-229.

(18) Nie, X.; Esopi, M. R.; Janik, M. J.; Asthagiri, A. Selectivity of $\mathrm{CO}_{2}$ Reduction on Copper Electrodes: The Role of the Kinetics of Elementary Steps. Angew. Chem. Int. Ed. 2013, 52, 2459-2462.

(19) Peterson, A. A.; Abild-Pedersen, F.; Studt, F.; Rossmeisl, J.; Norskov, J. K. How Copper Catalyzes the Electroreduction of Carbon Dioxide into Hydrocarbon Fuels. Energy Environ. Sci. 2010, 3, 1311-1315.

(20) Peterson, A. A.; Nørskov, J. K. Activity Descriptors for $\mathrm{CO}_{2}$ Electroreduction to Methane on Transition-Metal Catalysts. J. Phys. Chem. Lett. 2012, 3, 251-258.

(21) Back, S.; Kim, H.; Jung, Y. Selective Heterogeneous $\mathrm{CO}_{2}$ Electroreduction to Methanol. ACS Catal. 2015, 5, 965-971.

(22) Kim, K.-S.; Kim, W. J.; Lim, H.-K.; Lee, E. K.; Kim, H. Tuned Chemical Bonding Ability of Au at Grain Boundaries for Enhanced Electrochemical $\mathrm{CO}_{2}$ Reduction. $A C S$ Catal. 2016, 6, 4443-4448.

(23) Back, S.; Yeom, M. S.; Jung, Y. Active Sites of Au and Ag Nanoparticle Catalysts for $\mathrm{CO}_{2}$ Electroreduction to CO. ACS Catal. 2015, 5, 5089-5096. 